\title{
QUANTIFICAÇÃO DE FENÓIS TOTAIS EM SEMENTES DE MARACUJA AMARELO E DOCE
}

\author{
Nathália Aparecida Bragança Fávaris ${ }^{1}$ \\ Allan Rocha de Freitas ${ }^{2}$ \\ Cecilia Silva Valente ${ }^{3}$ \\ Manoel Victor Borges Pedrosa ${ }^{4}$ \\ Rodrigo Sobreira Alexandre ${ }^{5}$ \\ José Carlos Lopes ${ }^{6}$
}

Resumo: O Brasil apresenta elevado potencial edafoclimático para cultivo de maracujazeiros, cultura que se destaca na fruticultura nacional por apresentar acentuado crescimento e importância econômica. Todavia, há relatos de produtores quanto à baixa germinação de sementes de algumas espécies, o que pode estar associado à presença de fenóis. Objetivou-se com este trabalho quantificar os fenóis totais das sementes de frutos de maracujá amarelo (Passiflora edulis Sims f. flavicarpa Deg) e de maracujá doce (Passiflora alata Curtis). Os fenóis totais foram determinados em sementes inteiras e em embriões isolados. O delineamento experimental adotado foi o inteiramente casualizado, com quatro repetições de 25 sementes. Verificou-se que a maior concentração de fenóis totais encontra-se no embrião, quando comparado à semente inteira, e que a maior quantidade foi observada nas sementes de maracujá doce.

Palavras-chave: Passiflora alata Curtis; Passiflora edulis f. flavicarpa Deg.; Dormência; Inibidor.

\footnotetext{
1 Departamento de Produção Vegetal do Centro de Ciências Agrárias e Engenharias da Universidade Federal do Espírito Santo (CCAE-UFES), Brasil. E-mail: nath-braganca@hotmail.com.

2 Departamento de Produção Vegetal do Centro de Ciências Agrárias e Engenharias da Universidade Federal do Espírito Santo (CCAE-UFES), Brasil. E-mail: allanrochaf@gmail.com.

3 Departamento de Produção Vegetal do Centro de Ciências Agrárias e Engenharias da Universidade Federal do Espírito Santo (CCAE-UFES), Brasil. E-mail: cecisvalente@gmail.com.

4 Departamento de Produção Vegetal do Centro de Ciências Agrárias e Engenharias da Universidade Federal do Espírito Santo (CCAE-UFES), Brasil. E-mail: victorpedrosa2009@hotmail.com.

5 Departamento de Produção Vegetal do Centro de Ciências Agrárias e Engenharias da Universidade Federal do Espírito Santo (CCAE-UFES), Brasil. E-mail: rodrigosobreiraalexandre@gmail.com.

${ }^{6}$ Departamento de Produção Vegetal do Centro de Ciências Agrárias e Engenharias da Universidade Federal do Espírito Santo (CCAE-UFES), Brasil. E-mail: jclopes@bol.com.br.
} 